\title{
A performance measurement using balanced scorecard and structural equation modeling
}

\author{
Rosha Makvandi* and Payam Makvandi
}

Department of Management and Accounting, Alborz Branch, Islamic Azad University, Karaj, Iran

\begin{tabular}{l}
\hline C H R O N I C L E \\
\hline Article history: \\
Received June 28, 2013 \\
Received in revised format \\
19 October 2013 \\
Accepted 23 October 2013 \\
Available online \\
December 162013 \\
\hline Keywords: \\
BSC \\
Balanced scorecard \\
Performance measurement
\end{tabular}

\section{A B S T R A C T}

\begin{abstract}
During the past few years, balanced scorecard (BSC) has been widely used as a promising method for performance measurement. BSC studies organizations in terms of four perspectives including customer, internal processes, learning and growth and financial figures. This paper presents a hybrid of BSC and structural equation modeling (SEM) to measure the performance of an Iranian university in province of Alborz, Iran. The proposed study of this paper uses this conceptual method, designs a questionnaire and distributes it among some university students and professors. Using SEM technique, the survey analyzes the data and the results indicate that the university did poorly in terms of all four perspectives. The survey extracts necessary target improvement by presenting necessary attributes for performance improvement.
\end{abstract}

\section{Introduction}

There are literally various methods and techniques for measuring the relative performance of organizations. Balanced score card (BSC) is one of the most popular approaches for measuring the performance of organizations in terms of four perspectives including internal process, learning and growth, customer and financial figures. Kaplan and Norton are believed to be the first who established the idea of BSC (Kaplan \& Norton, 1996, 2000, 2002, 2004) and the idea has been widely used for performance measurement in different organizations (Bunker et al., 2004; Agrawal, 2008; Tohidi et al., 2010a, 2010b; Huang et al., 2011). Fig. 1 demonstrates the BSC structure. Kaplan and Norton (1996) believe that financial perspectives cannot be considered for measuring the performance of organization and the financial figures must be considered along with assessment of internal processes, capability of organization to learn and grow as well as the way firms deal with their customers. These figures are important especially in educational organizations where the objective of the firm is not solely to generate wealth in terms of dollar-value figures. There are literally many studies that indicate that BSC can be considered as a promising technique for measuring the relative performance of educational systems.

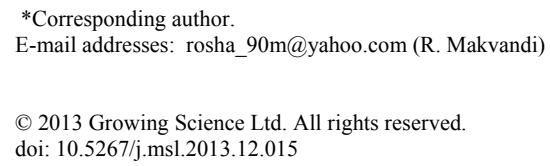


Mozaffari et al. (2012) performed a BSC method to measure the performance of a university based organization based on an adaptation of fuzzy numbers for handling the existing uncertainty on the numbers.

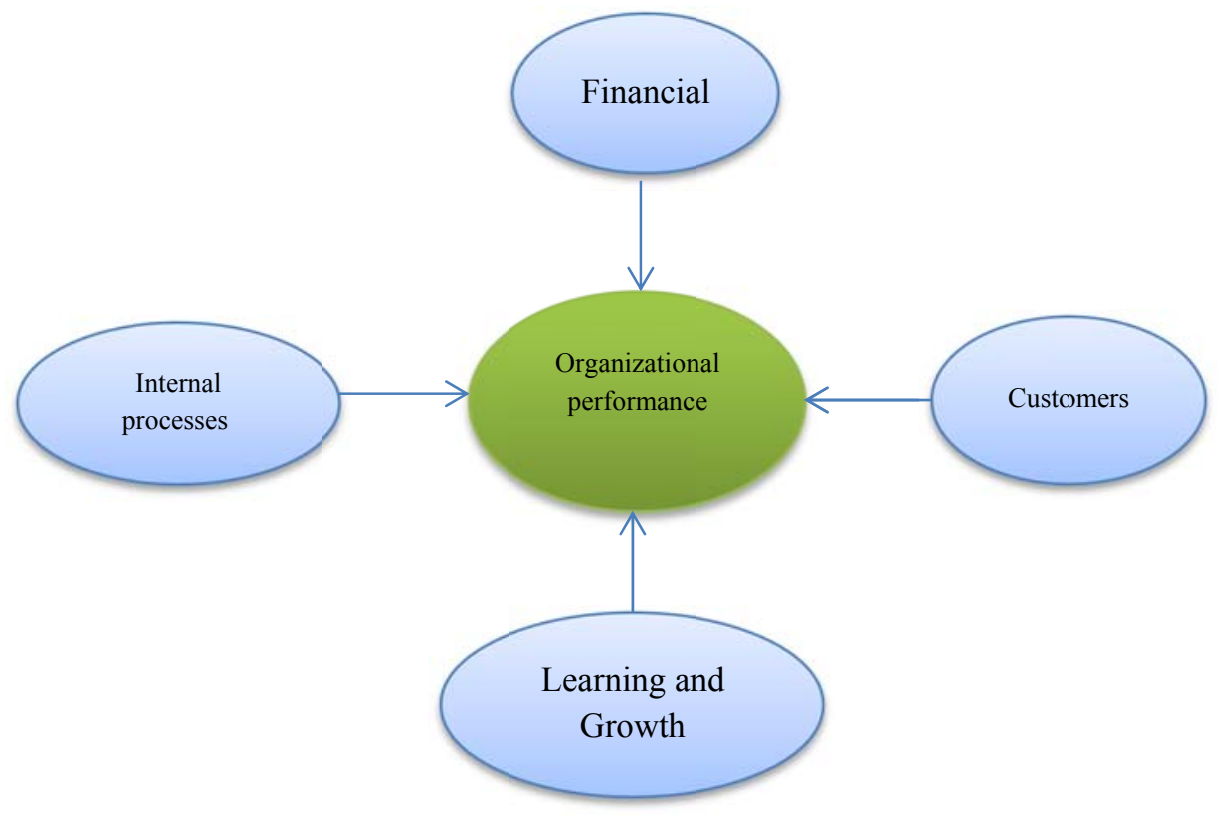

Fig. 1. The structure of the proposed study

According to Chen et al. (2006), the Taiwanese higher education sector was facing a significant challenge in terms of supply and demand and they examined how, in this scenario, the BSC could be applied for performance evaluation as a strategic management tool. They reported that to reach strategic themes it was necessary to propose specific and effective strategic goals. To assess progress and performance towards these strategic themes and targets, quantified performance measure indicators (PMIs) were recommended in a specific and simple manner, which allowed all staff members to understand the orientation of the BSC in fulfilling their daily tasks.

\section{The proposed study}

This paper presents a hybrid of BSC and structural equation modeling (SEM) to measure the performance of an Iranian university in province of Alborz, Iran. The sample size of the study is calculated as follows,

$n=\frac{N \times z_{\alpha / 2}^{2} \times p \times q}{\varepsilon^{2} \times(N-1)+z_{\alpha / 2}^{2} \times p \times q}$,

where $N$ is the population size, $p=1-q$ represents the yes/no categories, $z_{\alpha / 2}$ is CDF of normal distribution and finally $\varepsilon$ is the error term. Since we have $p=0.5, z_{\alpha / 2}=1.96$ and $N=3400$, the number of sample size is calculated as $n=384$. The proposed study of this paper uses this conceptual method, designs a questionnaire consists of 33 questions. The study distributed 400 questionnaires among some university students and professors and managed to collect 375 properly filled ones. In our survey, the first eight questions were associated with financial figures, questions 9-14 measured customers' characteristics, questions 15-22 we related to processes, questions 23-28 were associated with learning and growth and finally questions 29-33 measured the performance of organization. In our survey, $58.6 \%$ of the participants were male, they mostly had some university education and finally they were middle-aged people. There were four hypotheses associated with the study of this paper as follows, 
1. Internal processes influences on performance of organization.

2. Customers influences on performance of organization.

3. Learning and growth influences on performance of organization.

4. Financial capabilities influence on performance of organization.

The proposed study uses structural equation modeling as well as Pearson correlation ratios to examine the hypotheses of the survey.

\section{The results}

\subsection{The results of the implementation of SEM}

In this section, we present details of our investigation on testing various hypotheses of the survey. Fig. 2 demonstrates the summary of our results on the implementation of structural equation modeling.

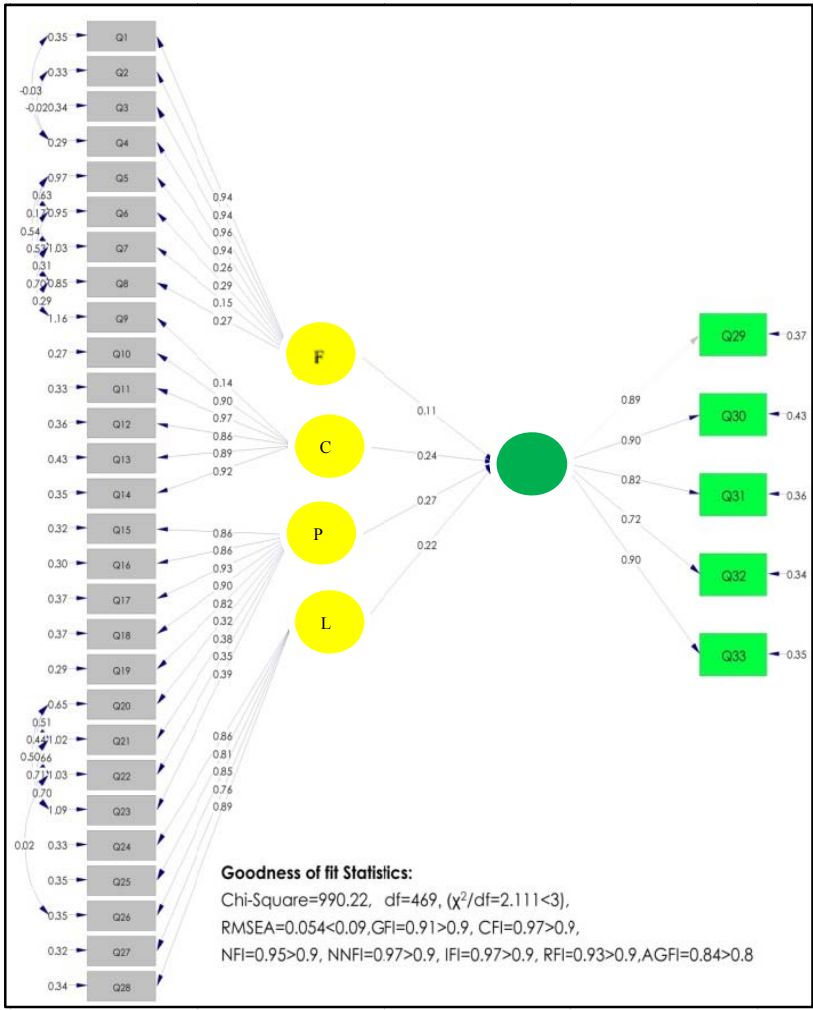

Standard data

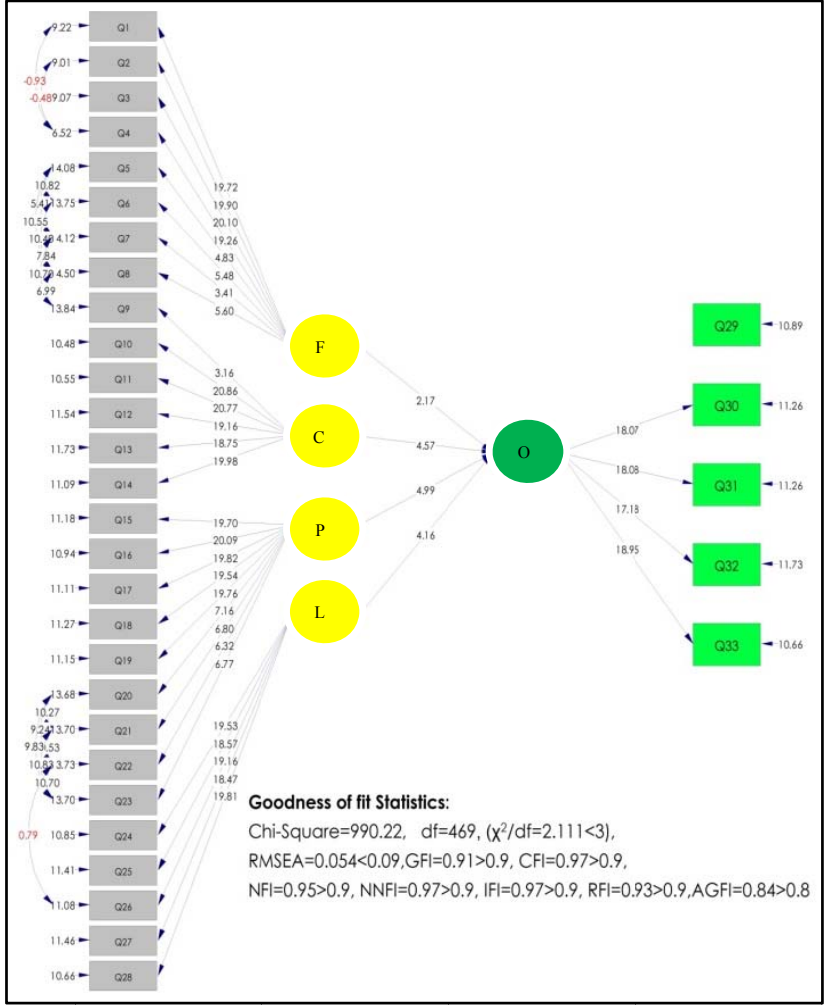

t-student values

F: Financial, C: Customer, P: Processes, L: Learning and growth O: Organizational performance

Fig. 2. The results of the implementation of SEM

Table 1 demonstrates the summary of some basic statistics associated with SEM implementation.

\section{Table 1}

The summary of statistics on SEM implementation

\begin{tabular}{lcccccccc}
\hline Statistics & Chi-square/df & GFI & RMSEA & CFI & NFI & NNFI & GFI & AGFI \\
\hline Value & 2.11 & 0.91 & 0.054 & 0.97 & 0.95 & 0.97 & 0.97 & 0.84 \\
Index & $<3$ & $>0.9$ & $<0.09$ & $>0.90$ & $>0.90$ & $>0.90$ & $>0.90$ & $>0.80$ \\
\hline
\end{tabular}


As we can observe from the results of Table 1, all statistics are within acceptable limits and we can accept the results SEM implementation. Table 2 shows details of our investigation.

\section{Table 2}

The summary of the results of the implementation of SEM

\begin{tabular}{lcccc}
\hline Hypothesis & $\beta$ & t-value & Sig. & Result \\
\hline Internal processes $\rightarrow$ organizational performance & 0.27 & 4.99 & 0.01 & Confirmed \\
Customers $\rightarrow$ organizational performance & 0.27 & 4.57 & 0.01 & Confirmed \\
Learning and growth $\rightarrow$ organizational performance & 0.22 & 4.16 & 0.01 & Confirmed \\
Financial capabilities $\rightarrow$ organizational performance & 0.11 & 2.17 & 0.01 & Confirmed \\
\hline
\end{tabular}

Note: $\mathrm{t}>1.96$ Is Significant at $\mathrm{P}<0.05, \mathrm{t}>2.58$ Is Significant at $\mathrm{P}<0.01$

As we can observe from the results of Table 2, all hypotheses are statistically meaningful when the level of significance is five percent. Now, we use t-student test on the performance evaluation questionnaire to see the effects of each four perspective on performance measurement.

\subsection{The effects of BSC factors on performance measurement}

In this subsection, we present details of the implementation of t-student to see the effects of various factors on the performance of private school.

\subsubsection{The effect of internal processes}

The first hypothesis is associated with the effect of internal processes on the performance of the case study of the paper. Note that all four hypotheses are examined as follows,

$$
\left\{\begin{array}{l}
H_{0}: \mu \leq 3 \\
H_{1}: \mu>3
\end{array}\right.
$$

The mean of scores devoted to internal processes is equal to 2.701 with t-student value of -8.814 and Sig. $=0.99$. This means that the internal processes are not within desirable value.

\subsubsection{The effect of customers}

The second hypothesis is associated with the effect of customers on the performance of the university. Similarly, the mean of scores devoted to internal processes is equal to 2.795 with t-student value of -5.677 and Sig. $=0.99$. This means that the customers are not within desirable value.

\subsubsection{The effect of learning and growth}

The third hypothesis is associated with the effect of learning and growth on the performance of the university. Similarly, the mean of scores devoted to learning and growth is equal to 2.666 with tstudent value of -9.770 and Sig. $=0.99$. This means that the customers are not within desirable value.

\subsubsection{The effect of financial}

The fourth hypothesis is associated with the effect of financial figures on the performance of the university. Similarly, the mean of scores devoted to financial figures is equal to 2.634 with t-student value of -10.549 and Sig. $=0.99$. This means that the customers are not within desirable value.

In summary, our survey indicates that the university is not presently in desirable status and there is a need to take necessary action to improve the performance of the university. 


\section{Conclusion and discussions}

In this paper, we have presented an empirical investigation to measure the performance of Islamic Azad University, which is located in province of Alborz, Iran. The proposed study has examined the performance of this school in terms of four BSC perspectives including learning and growth, internal processes, customers and financial figures. The proposed study has found out that the university was below the average desirable level in all four perspectives. Therefore, the university officials are required to improve the performance in all four perspectives. In terms of financial figures, it is suggested that the management team promote university professors when they make significant scientific achievements. The university must assign some grants to university professors, which are proportion to their high quality publication. This would help university professors support their graduate students and improve their capabilities. The university must expand its educational facilities such as physical equipment, etc. This helps increase the number of university students in the region, which increase financial figures.

In terms of customer, the university needs to improve the ranking of the university both domestically and internationally. This helps university build a better image and setup appropriate plan to compete with other high quality universities. In terms of internal processes, the university officials have to use better quality materials and keep update resources so that the university could graduate high quality people. In addition, the university is requested to use high skilled professionals for teaching various courses. In terms of learning and growth, the university officials have to learn more about the recent advances on technology and use them within the educational systems. The recent advances of technology have created tremendous opportunities for expanding educational systems through developing digital units so that all customers could attend university through online system.

\section{Acknowledgement}

The authors would like to thank the officials of Islamic Azad University for supporting the accomplishment of this paper. We are also delighted for constructive comments on earlier version of this paper.

\section{References}

Agrawal, S. (2008). Competency based balanced scorecard model: An integrative perspective. Indian Journal of Industrial Relations, 44(1), 12-18.

Bunker, R.D., Chang, H., Janakiraman, S.N., \& Konstans, C. (2004). A balanced scorecard analysis performance metrics. European Journal of Operational Research, 154(2), 423-436.

Chen, S.H., Yang, C.C., \& Shiau, J.Y. (2006). The application of balanced scorecard in the performance evaluation of higher education. The TQM Magazine, 18(2), 190-205.

Huang, H.C., Lai, M.C., \& Lin, L.H. (2011). Developing strategic measurement and improvement for the biopharmaceutical firm: Using the BSC hierarchy. Expert Systems with Applications, 38(5), 4875-4881.

Kaplan, R.S., \& Norton, D.P. (1996). Using the balanced scorecard as a strategic management system. Harvard Business Review (January.February). 74(1), 75-85.

Kaplan, R.S., \& Norton, D.P. (2000). The strategy-focused organization: How balanced scorecard companies thrive in the new business environment. Harvard Business School Press.

Kaplan, R.S., \& Norton, D.P. (2002). Building the Balanced Scorecard in Public Sector. Balanced Scorecard Report from Interview with Rick Pagsibigan, September 19.

Kaplan, R.S., \& Norton, D.P. (2004). Strategy maps: Converting intangible assets into tangible outcomes. Boston, MD: Harvard Bus. School Press.

Mozaffari, A., Kalaei, H., Shahhosseini, M \& Chaghouee, Y. (2013). A new framework for performance evaluation system using strategy map: A case study of Islamic Azad University of Semnan. Management Science Letters, 3(4), 1041-1048. 
Tohidi, H., Jafari, A., Azimi Afshar, A. (2010a). Strategic planning in Iranian educational organizations. Procedia Social and Behavioral Sciences, 2(2), 3904-3908.

Tohidi, H., Jafari, A., \& Azimi Afshar, A. (2010b). Using balanced scorecard in educational organizations. Procedia Social and Behavioral Sciences. 2(2), 5544-5548. 